\title{
SEM-EDS for determining the phosphorus content in activated sludge EPS
}

\author{
Danie J. Oosthuizen and Thomas E. Cloete
}

\section{Introduction}

The activated sludge system for wastewater treatment is one of today's most important biotechnological processes (Wagner et al., 1993). Although a considerable amount of work has been done on system design and process engineering, most systems designed for enhanced biological phosphorus removal (EBPR) routinely fail (Bond et al., 1995), necessitating chemical precipitation to meet effluent standards. This has been attributed to limited knowledge and understanding of the community structure-function and, consequently, the microbiology behind the activated sludge process (Ehlers et al., 1998). Understanding the microbial community of biological wastewater treatment systems would assist in improving design and performance (Bond et al., 1995; Cloete and Muyima, 1997). Studies on the microbial ecology of activated sludge in order to optimize the process have received much attention. A combination of classic culturedependent and molecular techniques have contributed to a better, but as yet incomplete understanding of the EBPR process and can be attributed to the intrinsic limitations of techniques used to study microbial population dynamics in natural habitats. Microbial diversity and, more importantly, the function of populations in a specific community have not been elucidated to date and, therefore, EBPR cannot be attributed as a function of a specific microbial population in activated sludge. Until now, it has not been possible to isolate a pure culture of bacteria that could be responsible for biological phosphorus removal (Ehlers et al., 1998). Also, very little is known about the microenvironment in activated sludge flocs, including the role of extracellular polysaccharides (EPS) in EBPR. Therefore methods other than classic culture dependent techniques need to be developed to differentiate between phosphorus-removing and nonphosphorus-removing systems and to study the mechanisms involved.

A large part of the floc structure in activated sludge is composed of EPS. These polymers are composed of sugars, amino acids and uronic acids (Bitton, 1994). However, the role of EPS in biological phosphorus removal has not been well studied. In previous studies, Buchan (1980) used energy dispersive spectrometry (EDS) to determine the location of phosphorus volutin granules in activated sludge, although little attention was paid to phosphorus located in the EPS outside these cell clusters.

EDS is a process whereby qualitative and quantitative analysis of a sample may be done following excitation of atoms in such a sample. Excitation of atoms leads to the production of X-rays, the energies of which differ for different elements. The spectrometer plots energies of these X-rays against specific counts of each specific energy, giving a compositional spectrum of the sample (Buchan, 1983). For this study, a combination of scanning electron microscopy (SEM) and EDS was chosen as a technique to study the role that EPS plays in phosphate removal from wastewater in the activated sludge process. Also, an investigation was done regarding amounts of EPS in different activated sludge plants by means of centrifugation extraction (Zhang et al., 1999) following homogenization with a sonic probe. Results, in combination with SEM-EDS, may account for different uptake abilities of different sludges. 


\section{Materials and methods}

\section{Sampling}

Four EBPR wastewater treatment plants (WTPs) situated in Pretoria, South Africa were sampled. Two of these (Rooiwal and Daspoort WTPs) were functioning exclusively biologically. The Baviaanspoort WTP employed ferric chloride, while the Centurion WTP used aluminium oxide as post-treatment for orthophosphate precipitation to meet effluent standards. These plants were sampled at the end of the aerobic zones before chemical addition. To standardize the experiments, $500 \mathrm{ml}$ of sludge at the end of the anaerobic or aerobic zones were drawn into sterile Schott bottles and transported on ice to the laboratory for processing.

\section{Orthophosphate analyses}

Orthophosphate analyses were done for the influent wastewater, as well as at the end of the aerobic zone directly before secondary settling. These analyses were done immediately after sampling for the Daspoort WTP and 45 min after sampling for the Rooiwal WTP. For the Baviaanspoort and Centurion WTPs, orthophosphate analyses were done on-site. The orthophosphate analyses were done using a SQ118 spectrophotometer (Merck) and the relevant test kit $\mathrm{P}(\mathrm{VM})$ after filtration of $10 \mathrm{ml}$ of sludge through Whatman no. 1 filter paper.

\section{Sample preparation}

$1 \mathrm{ml}$ of sludge from each sample was transferred to sterile $1.5 \mathrm{ml}$ Eppendorf tubes and washed three times with sterile double distilled water by centrifugation at $10000 \mathrm{rpm}$ for $5 \mathrm{~min}$ in a BHG Hermle $360 \mathrm{~K}$ centrifuge. The biomass pellet was finally resuspended in $1 \mathrm{ml}$ of sterile double distilled water. The samples were then diluted 1:10 in sterile double distilled water and $10 \mu \mathrm{l}$ spotted on high purity carbon stubs. These were left to air-dry at $37^{\circ} \mathrm{C}$ before being coated under vacuum with approximately $25 \mathrm{~nm}$ of high purity carbon. Two controls consisting of only a carbon stub without sample and a carbon stub containing only $10 \mu \mathrm{l}$ of sterile double distilled water were included to check the purities of both the carbon and double distilled water.

\section{EDS analysis}

Samples were analysed by means of EDS. The SEM used was a Jeol model JSM-5800LV using a backscatter detector for better compositional contrast and depth resolution than secondary electron detectors. Samples were analysed by a pre-standardized Noran Voyager system at $15 \mathrm{keV}$ for a livetime of $100 \mathrm{~s}$. Ten analyses of each sample were done. Digital images were captured by means of an Orion frame-grabber.

\section{EPS extraction}

For the EPS extraction, the regular centrifugation method of Zhang et al. (1999) was used, but instead of homogenization by means of blending, homogenization in this case was done with a Cole-Palmer (Series 4710) ultrasonic homogenizer probe with an output of 55\%. This method was preferred to other methods as reported by Zhang et al. (1999) as it was reported to have the least contamination by protein and DNA. Five Eppendorff tubes were filled with $750 \mu \mathrm{l}$ of sludge for each of the Baviaanspoort and Centurion WTPs. Samples were centrifuged at $3500 \mathrm{rpm}$ for $10 \mathrm{~min}$ and the supernatant removed. The tubes were again filled with $750 \mu \mathrm{l}$ double distilled water and homogenized with three $15 \mathrm{~s}$ bursts. Samples were kept on ice during homogenization steps. After homogenization, the previously removed fractions were added to the tubes and the samples centrifuged for $30 \mathrm{~min}$ at $12000 \mathrm{rpm}$. After centrifugation, the supernatant was pooled and filtered through $0.22 \mu$ MILLEX ${ }^{\circledR}$ GS syringe filters (Millipore) into McCartney bottles and freeze-dried overnight. 


\section{Results and discussion}

At the time of sampling all the WTPs produced effluents which conformed to the special standard of 1 mg. $1^{-1}$ orthophosphate discharged to water sources as stipulated in the Republic of South Africa Water Act of 1956, as amended in 1980 (Slim, 1987).

There are many problems associated with EDS of biological samples, as normal preparation techniques for electron microscopy can displace, transform and dissolve many elements within biological samples, and are therefore not representative of the in vivo situation (Buchan, 1980). In this study we avoided normal SEM preparation to minimize the abovementioned problems.

SEM indicated that the Daspoort and Rooiwal EBPR sludges seemed to consist of clusters of cells (Figures 1 and 2). The Baviaanspoort and Centurion sludges contained more filamentous organisms than Rooiwal and Daspoort (Figures 3 and 4).

On average, cell clusters with associated EPS from the four EBPR sludges contained between 57 and $59 \%$ phosphorus (Table 1, Figure 5), while EPS alone contained between 23 and 30\% phosphorus (Table 1, Figure 6). These values also showed little variation amongst different plants and different zones in the same plant (Daspoort) (Table 1).

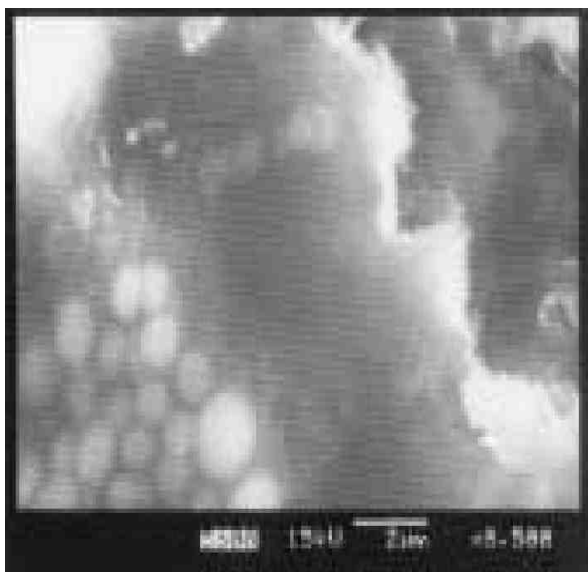

Figure 1 Electron micrograph indicating the spatia distribution of cell clusters and EPS in a Daspoort sludge sample

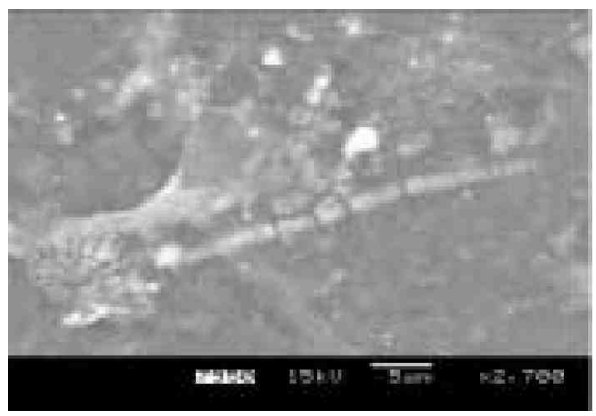

Figure 3 Electron micrograph indicating the spatial distribution of EPS and cell clusters in Baviaanspoort sludge. Note the filamentous organism

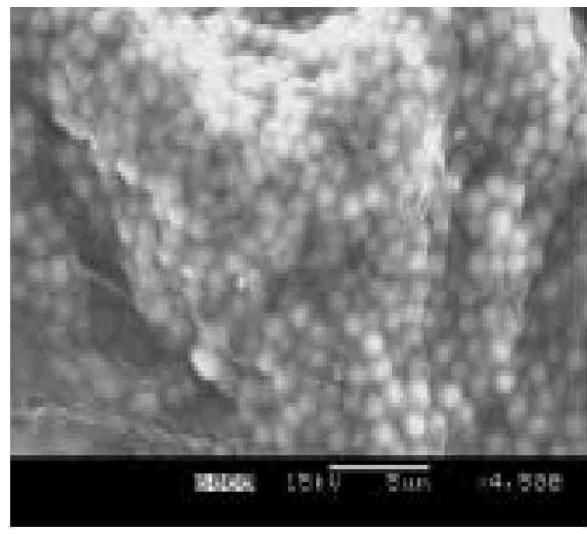

Figure 2 Electron micrograph indicating the spatial distribution of cell clusters and EPS in a Rooiwal sludge sample

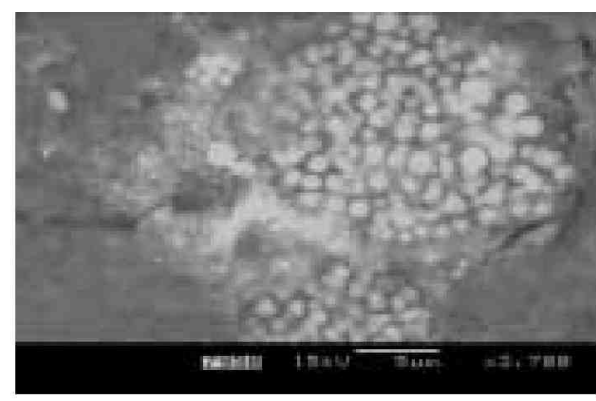

Figure 4 Electron micrograph indicating the spatial distribution of EPS and cell clusters in Centurion sludge 
Table 1 EDS analysis of cell clusters and EPS of different activated sludge plants and zones of the same plant

Description range (\%)

Daspoort - cell clusters (anaerobic zone)

Daspoort - cell clusters (aerobic zone)

Rooiwal - cell clusters (anaerobic zone)

Baviaanspoort - cell clusters (aerobic zone)

Centurion - cell clusters (aerobic zone)

Daspoort - EPS (anaerobic zone)

Daspoort - EPS (aerobic zone)

Rooiwal - EPS (anaerobic zone

Baviaanspoort - EPS (aerobic zone)

Centurion - EPS (aerobic zone)

Average (\%) Standard deviation (\%)

\begin{tabular}{lll}
$55-60$ & 58 & 2 \\
$51-59$ & 57 & 2 \\
$56-64$ & 59 & 3 \\
$53-60$ & 57 & 2 \\
$56-60$ & 57 & 1 \\
$23-37$ & 30 & 8 \\
$19-33$ & 27 & 4 \\
$16-35$ & 29 & 8 \\
$20-40$ & 30 & 1 \\
$17-30$ & 23 & 2 \\
\hline
\end{tabular}

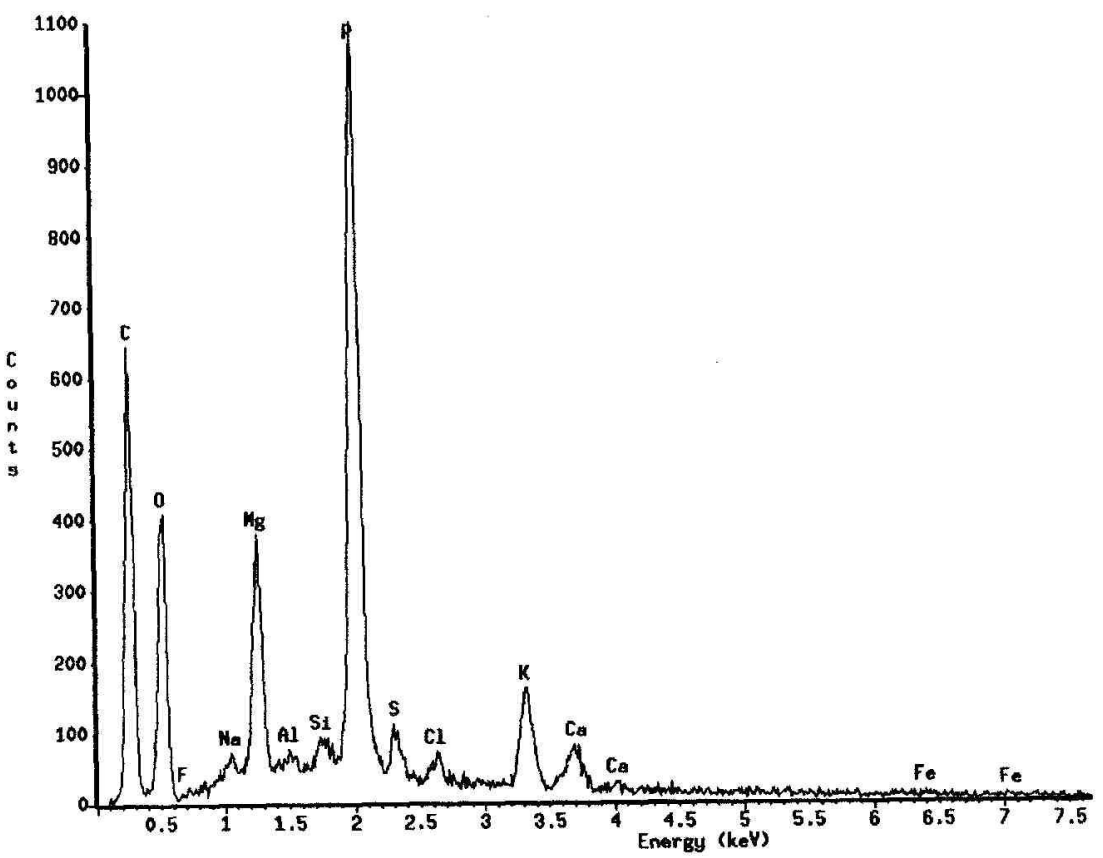

Figure 5 Analytical X-ray spectrum of Daspoort anaerobic sludge cell clusters 


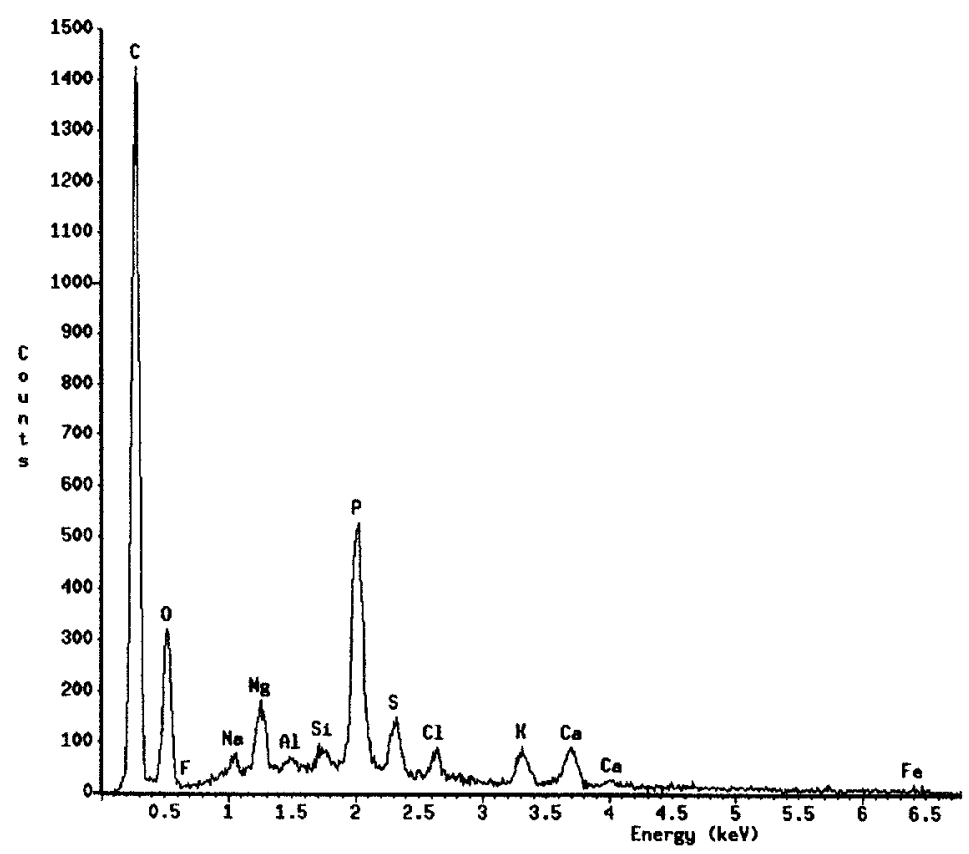

Figure 6 Analytical X-ray spectrum of Daspoort anaerobic sludge EPS

As counter-ions to phosphorus, magnesium, potassium and calcium were dominant in cell clusters, while, in addition to these ions, sulphur, and silicon ions were also found as counter-ions in EPS (Tables 2, 3 and 4). Baviaanspoort cell clusters and EPS was found to be rich in iron, probably due to recycling of sludge after chemical treatment (Table 4). The EPS of Centurion sludge was rich in iron and aluminium. The aluminium was probably present due to recycling of sludge after chemical treatment and the iron due to the influent metal concentration (Table 3). Copper was also found in the Centurion EPS (data not shown).

It was easy to distinguish between bacterial cells and EPS for the Daspoort and Baviaanspoort sludges, making EDS analysis easy (Figures 1 and 3). However, due to the very close encapsulation of cells by the EPS in the Rooiwal and Centurion sludges (Figures 2 and 4), EDS analysis was more difficult. Cell clusters of these sludges may also have contributed to X-rays produced from EPS being analyzed, due to overlap of EPS and cells in the large excitation volume (approximately $2 \mu \mathbf{x} 2 \mu$ ) created.

EDS analyses of phosphorus in cell clusters in this study [60\% (cells and EPS) minus

Table 2 Typical data set for analysis of cell clusters and EPS (Rooiwal - anaerobic zone). The K following every element indicates the K-shell of the specific atom

\begin{tabular}{cccccc}
\hline Element & $\begin{array}{c}\text { Cell clusters } \\
\text { Weight \% }\end{array}$ & SD (\%) & Element & $\begin{array}{c}\text { EPS } \\
\text { Weight \% }\end{array}$ & SD (\%) \\
\hline Na-K & 0.89 & 0.60 & Na-K & 3.59 & 0.59 \\
Mg-K & 17.83 & 0.91 & Mg-K & 9.28 & 0.41 \\
Al-K & 0.08 & 0.55 & Al-K & 5.90 & 0.63 \\
Si-K & 0.46 & 0.50 & Si-K & 8.71 & 0.37 \\
P-K & 59.92 & 1.48 & P-K & 35.45 & 1.00 \\
S-K & 0.96 & 0.77 & S-K & 12.35 & 0.55 \\
Cl-K & 1.07 & 0.72 & Cl-K & 1.79 & 0.41 \\
K-K & 18.79 & 1.73 & K-K & 12.41 & 0.52 \\
Ca-K & 0.00 & 0.00 & Ca-K & 6.82 & 0.49 \\
Fe-K & ND & ND & Fe-K & 3.72 & 1.00 \\
\hline
\end{tabular}


Table 3 Typical data set for analysis of cell clusters and EPS (Centurion - aerobic zone). The K following every element indicates the K-shell of the specific atom

\begin{tabular}{cccccc}
\hline Element & $\begin{array}{c}\text { Cell clusters } \\
\text { Weight \% }\end{array}$ & SD (\%) & Element & $\begin{array}{c}\text { EPS } \\
\text { Weight \% }\end{array}$ & SD (\%) \\
\hline Na-K & 0.00 & 0.00 & Na-K & 0.68 & 1.11 \\
Mg-K & 15.91 & 0.82 & Mg-K & 1.59 & 0.93 \\
Al-K & 1.31 & 0.51 & Al-K & 25.55 & 1.00 \\
Si-K & 0.15 & 0.48 & Si-K & 5.76 & 1.04 \\
P-K & 57.12 & 1.36 & P-K & 23.29 & 1.20 \\
S-K & 1.33 & 0.73 & S-K & 5.69 & 1.19 \\
Cl-K & 0.00 & 0.00 & Cl-K & 3.23 & 1.12 \\
K-K & 16.68 & 0.80 & K-K & 0.48 & 1.03 \\
Ca-K & 6.37 & 0.78 & Ca-K & 14.95 & 1.27 \\
Fe-K & 1.14 & 1.52 & Fe-K & 18.77 & 3.27 \\
\hline
\end{tabular}

Table 4 Typical data set for analysis of cell clusters and EPS (Baviaanspoort - aerobic zone). The K following every element indicates the K-shell of the specific atom

\begin{tabular}{cccccc}
\hline Element & $\begin{array}{c}\text { Cell clusters } \\
\text { Weight \% }\end{array}$ & SD (\%) & Element & $\begin{array}{c}\text { EPS } \\
\text { Weight \% }\end{array}$ & SD (\%) \\
\hline Na-K & 0.00 & 0.00 & Na-K & 1.34 & 0.49 \\
Mg-K & 14.98 & 1.42 & Mg-K & 3.93 & 0.38 \\
Al-K & 1.36 & 0.91 & Al-K & 2.38 & 0.35 \\
Si-K & 2.18 & 0.83 & Si-K & 3.09 & 0.35 \\
P-K & 53.73 & 2.10 & P-K & 26.27 & 0.90 \\
S-K & 1.82 & 1.29 & S-K & 9.63 & 0.94 \\
Cl-K & 0.00 & 0.00 & Cl-K & 0.99 & 0.42 \\
K-K & 8.05 & 1.11 & K-K & 1.92 & 0.42 \\
Ca-K & 10.05 & 1.27 & Ca-K & 19.44 & 1.14 \\
Fe-K & 7.84 & 2.74 & Fe-K & 31.01 & 1.78 \\
\hline
\end{tabular}

$30 \%$ (EPS alone) equaling 30\%] are in agreement with those of Buchan (1980), who indicated an 18\%) phosphorus content in Acinetobacter cells.

Jenkins et al. (1971) reviewed various aspects of chemical precipitation of phosphorus. According to their theory, phosphorus uptake in excess of the normal metabolic requirements of organisms in activated sludge is caused by chemical precipitation of phosphates by metals. These precipitates are then entrapped in the sludge matrix. Compounds such as monetite $\left(\mathrm{CaHPO}_{4}\right)$, hydroxyapatite $\left[\mathrm{Ca}_{5}\left(\mathrm{PO}_{4}\right)_{3} \mathrm{OH}\right]$, tricalcium phosphate $\left[\mathrm{Ca}_{3}\left(\mathrm{PO}_{4}\right)_{2}\right]$ and octacalcium phosphate $\left[\mathrm{Ca}_{4} \mathrm{H}\left(\mathrm{PO}_{4}\right)_{3}\right]$ have been considered to be precipitated. Morgan and Fruh (1972) also considered magnesium and iron precipitates. According to the theory of Kerdachi and Roberts (1980), colloidal calcium phosphate crystals are precipitated through mediation of bacterial extracellular enzymes. These crystals are then supposedly chemically bound to an extracellular polymer matrix of microbial origin. Adsorptive properties of exopolymers have been well documented, especially in terms of biosorption of pollutants and toxics (Beech and Cheung, 1995; Loaëc et al., 1997). Results of EDS analyses of EPS for the Baviaanspoort and Centurion WTPs in this study tend to support the abovementioned theories to a certain extent, as chemical precipitation of orthophosphate with iron and aluminium follows the stoichiometry of 1:1 (Bitton, 1994) (Tables 3 and 4). EPS extraction from the Baviaanspoort and Centurion WTPs led to different yields from similar volumes of sludge (Figure 7). Analysis of these bulk samples is currently underway. However, there is no way of knowing to what extent orthophosphate contamination of the EPS fractions occurred during homogenization due to cell breakage or lysis and further steps to prevent this phenomenon should be investigated. 


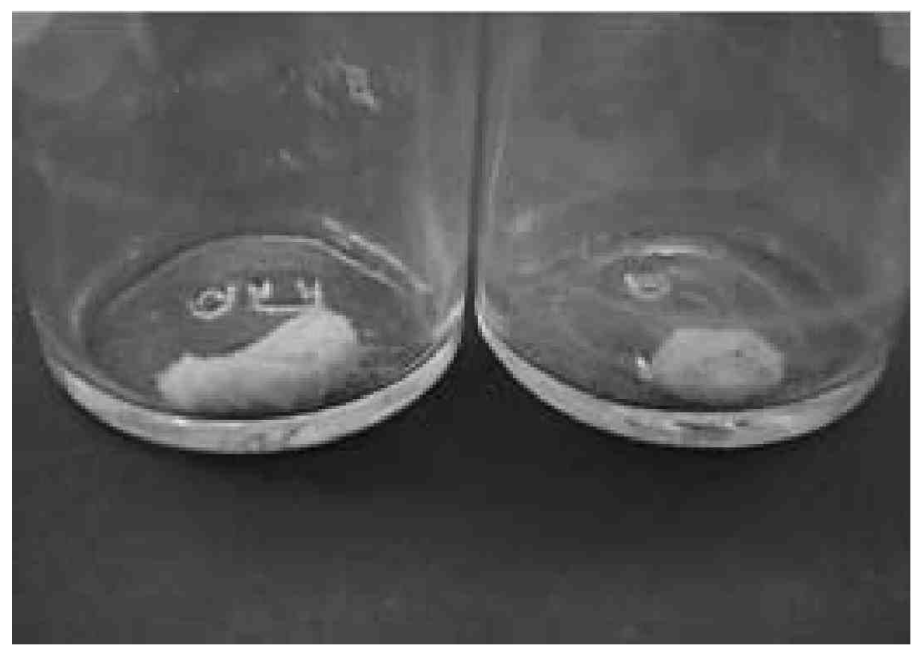

Figure 7 Comparison of different EPS yields following extraction after homogenization with a sonic probe. Samples are from left to right Baviaanspoort and Centurion.

Further attempts to optimize the EDS analysis will be investigated. This will include Transmission Electron Microscopy (TEM) in combination with EDS to avoid large excitation volumes, as well as rapid freezing or cryosectioning to avoid displacement or migration of ions inside the samples.

\section{Conclusions}

SEM-EDS indicated that cell clusters with associated EPS of different activated sludge plants, on average, contained between 57 and 59\% phosphorus, while EPS alone contained on average between 23 and 30\% phosphorus. Results suggest that phosphorus removal in activated sludge might be due not only to PAO, but also to EPS acting as a phosphorus reservoir. Different spatial distributions of EPS for different sludges following airdrying and coating with carbon under vacuum may indicate different kinds of EPS in different systems. Different EPS yields following extraction from similar volumes of sludge, and by following the same homogenization procedure, may explain differences in the phosphate uptake ability of different systems.

\section{Acknowledgement}

The authors thank the Unit for Microscopy and Microanalysis at the University of Pretoria for analyses as well as their valuable contributions to this research. This study was funded by the Water Research Commission of South Africa.

\section{References}

Beech, I.B. and Cheung, C.W.S. (1995). Interactions of exopolymers produced by sulphate-reducing bacteria with metal ions. Int. Biodeterior. Biodegrad., 35, 59.

Bitton, G. (1994). Wastewater Microbiology. John Wiley \& Sons, New York.

Bond, P.L., Hugenholtz, J.K., Keller, J. and Blackall, L.L. (1995). Bacterial community structure of phosphate- removing and non-phosphate-removing activated sludge from sequencing batch reactors. Appl. Environ. Microbiol., 61, 1910-1916.

Buchan, L. (1980). The location and nature of accumulated phosphorus in activated sludge. DSc (Agric) thesis, University of Pretoria, Pretoria, South Africa.

Buchan, L. (1983). Possible biological mechanism of phosphorus removal. Wat. Sci. Tech., 15(314), 87-103.

Cloete, T.E. and Muyima, N.Y.U. (1997). Microbial Community Analysis: The Key to the Design of Biological Wastewater Treatment Systems. (IAWQ Scientific and Technical Report No 5) International Association on Water Quality, London, Great Britain.

Ehlers, M.M., Erasmus, A. and Cloete, T.E. (1998). Fingerprinting of Activated Sludge Systems Using PAGE Analysis of Total 
Protein Extractions for the Optimization of Biological Phosphorus Removal, Water Research Commission Report No. 776/1/98, Water Research Commission, Pretoria, South Africa.

Jenkins, D., Menar, A.B. and Ferguson, J.F. (1971). Chemical processes for phosphate removal. Wat. Res., 5, $369-389$.

Kerdachi, D.A. and Roberts, M.R. (1980). The ability of the extended aeration activated sludge process to remove phosphorus consistently to less than $0,1 \mathrm{mg}$ P/l in a simple surface aerated reactor. Presented to the S.A. Branch of the Institute of Water Pollution Control Conference, Pretoria, June 1980.

Loaëc, M., Olier, R. and Guezennec, J. (1997). Uptake of lead, cadmium and zinc by a novel bacterial exopolysaccharide. Wat. Res., 31, 1171-1179.

Morgan, W.E. and Fruh, E.G. (1972). An investigation of phosphorus removal mechanisms in activated sludge systems, Environmental Protection Technology Series, EPA-R2-72-031, Office of Research and Monitoring, U.S. Environmental Protection Agency, Washington D.C.

Slim, J.A. (1987). Some developments in the water industry in South Africa. Wat. Pollut. Control, 86, $262-271$.

Wagner, M., Amann, R., Lemmer, H. and Schleifer, K.C. (1993). Probing activated sludge with oligonu-cleotides specific for proteobacteria: Inadequacy of culture-dependent methods for describing microbial community structure. Appl. Environ. Microbiol, 59, 1520-1525.

Zhang, X., Bishop, P.L. and Kinkle, B.K. (1999). Comparison of extraction methods for quantifying extracellular polymers in biofilms. Wat. Sci. Tech., 39(7), 211-218. 